\title{
Promoting diversity and equality across surgical specialties
}

\section{Marc R. Moon (1)}

In 2020, Nature Reviews Urology made a pledge to actively address bias and discrimination in urology ${ }^{1}$. In a Viewpoint article (Rising Black voices in urology - the next generation. Nat. Rev. Urol. 18, 327-335 (2021)), twelve medical students discussed how urology programmes can better appeal to Black students through active mentorship and representation ${ }^{2}$. Similar to urology, the surgical subspecialty of cardiothoracic surgery is not a core component of the standard medical school curriculum and requires an extra effort to attract trainees. The lack of diversity in cardiothoracic surgery among faculty members and residents is comparable to the one observed in urology. The percentage of women and under-represented in medicine (UIM, defined by the Association of American Medical Colleges as racial and ethnic populations under-represented in medicine relative to their percentage in the general population) in cardiothoracic surgery is even lower than in urology ${ }^{3}$. In 2019, women accounted for $8 \%$ of cardiothoracic surgeons compared with $9.5 \%$ of urologists ${ }^{4}$. Among cardiothoracic surgery residents, 26\% are women and 9.5\% are UIM (3\% Black), similar to the situation in urology, in which $28 \%$ of residents are women and $11 \%$ are UIM (3.8\% Black). Achua and colleagues ${ }^{2}$ note that mentorship and representation are essential to promote interest in non-core specialties, but we have to do it right ${ }^{2,5}$.

A survey published in the American Surgeon reported specialty recommendations from American College of Surgeons' mentors to female mentees ${ }^{6}$. The specialty that was the least recommended to women was cardiothoracic surgery. In the survey, $20 \%$ of urologists advised only men to pursue urology as a specialty, whereas $57 \%$ of cardiothoracic surgeons advised only men to pursue cardiothoracic surgery. These data indicate that urologists are demonstrating far less sexism than cardiothoracic surgeons, which should help turn the tide in urology moving forward.

Trainees entering cardiothoracic surgery reported that two of the most important factors for choosing the field are the presence of a role model in the specialty and having a good experience on a rotation ${ }^{7}$. Faculties in surgical subspecialties need to ensure medical student rotations are a positive experience. Three factors are considered to be crucial during a surgical clerkship: one-on-one resident mentoring; experiencing a meaningful relationship with a patient; and making an incision and assisting in dissection ${ }^{8}$, all of which could be easily implemented in both cardiothoracic surgery and urology.

Diversity in surgical subspecialties will not occur passively, but requires a concerted effort. In 2021, the American Association for Thoracic Surgery foundation introduced a $\$ 1.2$ million Medical Student Diversity Scholarship programme to support UIM students interested in cardiothoracic surgery ${ }^{9,10}$. The purpose of these \$20,000-per-year scholarships is to discourage UIM students from seeking part-time, non-educational jobs that can interfere with class attendance, study efforts, research opportunities and work-life balance for both students and their families. This programme has the potential to increase the number of UIM cardiothoracic surgery trainees by $83 \%$ by 2026 . Similar programmes could be implemented for students interested in urology to promote equality and equity in the field.

Everyone should applaud Nature Reviews Urology for their commitment to improve diversity in urology $y^{1}$, but they are not alone. Reaching diversity, equality and equity is a crucial mission for almost every surgical subspecialty to advance knowledge, build a non-confrontational community of surgeons and improve patient health.

Marc R. Moon iD

Division of Cardiothoracic Surgery, Washington University School of Medicine, St. Louis, MO, USA. e-mail:moonm@wustl.edu https://doi.org/10.1038/s41585-021-00548-z

1. Black lives in urology: addressing the bias and redressing the balance. Nat. Rev. Urol. 17, 423 (2020)

2. Achua, J. K. et al. Rising Black voices in urology - the next generation. Nat. Rev. Urol. 18, 327-335 (2021).

3. Moon, M. R. Equal means equal: cardiothoracic surgery in its second century. J. Thorac. Cardiovasc Surg. 161, 1381-1389 (2021).

4. Association of American Medical Colleges. 2020 physician specialty data report: active physicians by sex and specialty, 2019. AAMC https://www.aamc.org/ data-reports/workforce/interactive-data/activephysicians-sex-and-specialty-2019 (2020)

5. Luc, J. G. Y., Preventza, O., Moon, M. R. \& Antonoff, M. B. Keep the pipeline open for women applying to cardiothoracic surgery. Am. Surg. 87, 162-163 (2021).

6. Altieri, M. S., Price, K. L., Yang, J., Jones, D. B. $\&$ Pryor, A. D. What are women being advised by mentors when applying to surgery? Am. Surg. 86 266-272 (2020).

7. Vaporciyan, A. A. et al. Factors affecting interest in cardiothoracic surgery: survey of North American general surgery residents. J. Thorac. Cardiovasc. Surg 137, 1054-1062 (2009).

8. McKinley, S. K. et al. Identification of specific educational targets to improve the student surgical clerkship experience. J. Surg. Res. 254, 49-57 (2020).

9. Moon, M. R. Is this an adventure? J. Thorac. Cardiovasc. Surg. 162, 907-916 (2021).

10. Moon, M. R. Diversity in cardiothoracic surgery: the time has come. Asian Cardiovasc. Thorac. Ann. 29, 877-883 (2021).

Competing interests

The author declares no competing interests. 